\title{
Sid New Disease Reports \\ First report of Pleospora herbarum causing brown leaf blight of Chinese chive in Japan
}

T. Misawa $^{1 *}$, D. Kurose ${ }^{2}$, S. Tsushima ${ }^{3}$ and T. Sato ${ }^{4}$

${ }^{1}$ Donan Agricultural Experiment Station, Hokkaido Research Organization, Honcho, Hokuto, Hokkaido 041-1201, Japan; ${ }^{2}$ CABI Europe-UK, Bakeham Lane, Egham, Surrey TW20 9TY, UK; ${ }^{3}$ Environmental Biofunction Division, National Institute for Agro-Environmental Sciences, Kannondai, Tsukuba, Ibaraki 305-8604, Japan; ${ }^{4}$ Genetic Resources Center, National Institute of Agrobiological Sciences, Kannondai, Tsukuba, Ibaraki 305-8602, Japan

*E-mail: misawa-tomoo@hro.or.jp

Received: 30 Nov 2015. Published: 08 Aug 2016. Keywords: Allium tuberosum, Stemphylium herbarum

Chinese chive (Allium tuberosum) is a popular vegetable in Chinese and Korean cuisines. A new disease was observed in four fields during routine disease surveys of Chinese chive conducted in June and September from 2007 to 2012 in Hokkaido, Japan. The incidence ranged from 5 to $20 \%$. Symptoms first appeared as white to pale brown fusiform lesions, about 3-8 cm in length, on the centres of leaves (Figs. 1, 2a). Parts of the lesions became pink (Fig. 2b) and then turned dark brown. Finally, the upper parts of leaves with lesions died. Sooty conidial masses were observed at the centres of the lesions (Fig. 2c).

A fungal isolate Mt41 was obtained from lesions on leaves showing typical symptoms. Conidiophores of the isolate grown on V8 juice agar medium were erect, pale to mid brown, 27-138 $\mu \mathrm{m}$ long and 4.5-6.5 $\mu \mathrm{m}$ wide, with swellings at the distal ends. They developed by percurrent proliferation and bore single conidia at their apices. Conidia were oblong to ellipsoid, muriform with 1-3 (-4) transverse and 1-3 longitudinal septa, constricted at the median transverse septum, pale to mid-brown, verruculose, 19-43 $\times$ 14-30 (mean $32 \times 23$ ) $\mu \mathrm{m}$, with a length to breadth ratio of 1.0-1.8 (mean 1.4) (Fig. 3). The isolate formed pseudothecia that were black, globose with short beaks, and with mean dimensions of $515 \times 469 \mu \mathrm{m}$ (Fig. 4). The bitunicate asci were transparent, clavate and 171-254 $\times 27-34 \mu \mathrm{m}$, containing eight ascospores. The ascospores were monoseriate to biseriate, pale brown, oblong, 31-45 $\times 14-19 \mu \mathrm{m}$, with 7 transverse and 1-3 longitudinal septa (Fig. 5). These morphological characteristics were similar to those of Pleospora herbarum and P. tarda as described by Simmons (1985). Therefore, species identification requires molecular analysis in this genus. Previously we conducted a molecular phylogenetic analysis based on four loci and found that isolate Mt 41 is closely related to the type/ex-type strain of $P$. herbarum (GenBank Accession Nos. AB979877, AB979906, AB979936 and AB979966) (Kurose et al., 2015). Therefore, the isolate was identified as $P$. herbarum.

Pathogenicity tests were performed on four-month-old Chinese chive plants (cv. Powerful-Greenbelt) grown in plastic pots $(16 \mathrm{~cm}$ diameter, $19 \mathrm{~cm}$ deep). Ten leaves of each plant were wounded with a needle then covered with gauze $(1.5 \times 10 \mathrm{~cm})$. A conidial suspension $\left(10^{5}\right.$ spores $\left./ \mathrm{ml}\right)$, or sterilised distilled water as a control, was dripped onto the gauze, then the leaves were wrapped with plastic paraffin film. Inoculated and control plants were covered with plastic bags and grown in a chamber at $15^{\circ} \mathrm{C}$ with a $16 \mathrm{~h}$ photoperiod. The plastic bags, film and gauze were removed five days after inoculation. The inoculation test comprised one pot. The symptoms were reproduced on all inoculated leaves 11 days after inoculation. Control plants remained healthy. The causal fungus was reisolated from inoculated leaves, thus fulfilling Koch's postulates.

Leaf tip blight of Chinese chive caused by $S$. vesicarium has been reported in Korea (Chang<> et al., 2000). A previous paper described the taxonomy of Stemphylium herbarum isolated from Chinese chive in Japan (Kurose et al., 2015). Kurose et al. (2015) did not provide full details of pathogen identification or disease occurrence. This current paper is the first detailed description of the disease in Japan and confirmation of the teleomorph Pleospora herbarum as the causal agent. The isolate Mt41 was deposited in the National Institute of Agrobiological Sciences Genebank, Japan as MAFF 241964

\section{References}

Chang SW, Kim HD, Kang HJ, Hwang BK, 2000. Leaf blight of Chinese chive caused by Stemphylium vesicarium in Korea. The Plant Pathology Journal 16, 280-282.

Kurose D, Misawa T, Suzui T, Ichikawa K, Kisaki G, Hoang LH, Furuya N, Tsuchiya K, Tsushima S, Sato T, 2015. Taxonomic re-examination of several Japanese Stemphylium strains based on morphological and molecular phylogenetic analyses. Journal of General Plant Pathology 81, 358-367. http://dx.doi.org/10.1007/s10327-015-0607-x

Simmons EG, 1985. Perfect states of Stemphylium. II. Sydowia 38, 284-293.

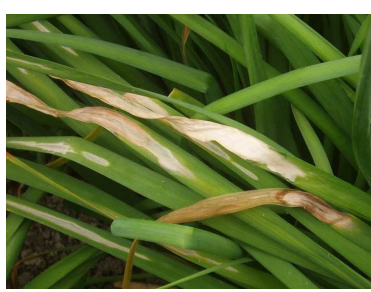

Figure 1

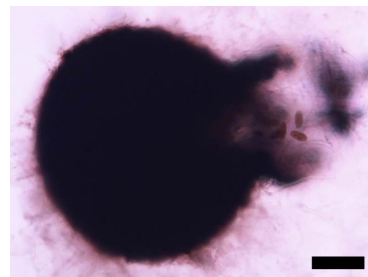

Figure 2
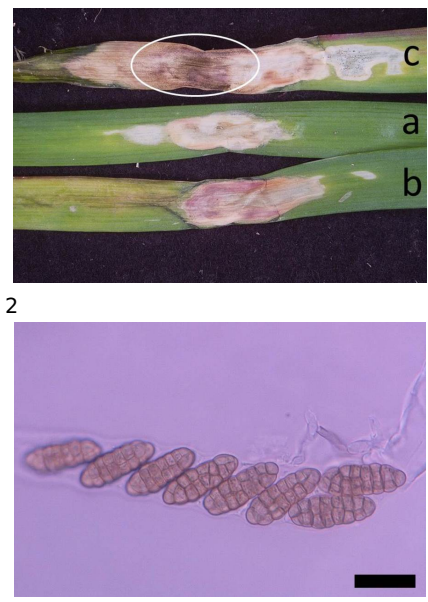

Figure 5

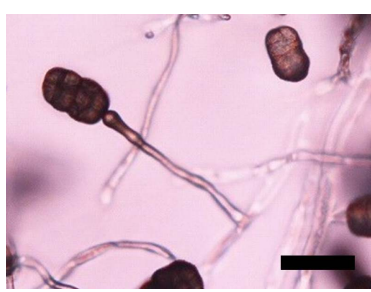

Figure 3

Figure 4

To cite this report: Misawa T, Kurose D, Tsushima S, Sato T, 2016. First report of Pleospora herbarum causing brown leaf blight of Chinese chive in Japan. New Disease Reports 34, 5. http://dx.doi.org/10.5197/j.2044-0588.2016.034.005

(c) 2016 The Authors

This report was published on-line at www.ndrs.org.uk where high quality versions of the figures can be found. 